\title{
Knowledge, attitude and practices in relation to prevention and control of schistosomiasis infection in Mwea Kirinyaga
} county, Kenya

\author{
J Mwai* ${ }^{*}$, S Njenga and M Barasa
}

\begin{abstract} technique. NUIRO.6 software. status $(p=0.71)$, wearing of protedive, gear $(p=0.142)$ and working on the paddies $(p=0.144)$. io sificar, y reduce the transmission and morbidity from schistosomiasis.

worus: Knowledge, Attitude, Practice, Prevention, Control, Schistosomiasis, Mwea

(Con, nued on next page)
\end{abstract}

Background: Schistosomiasis remains a major public health problem in Ken a. adequate knowledge, attitudes and practices (KAP) on causative factors are some of the critical factors for in prevalence. The study assessed KAP on the control and prevention of schistosomiasis infection in M division, Kirinyaga County-Kenya. Four hundred and sixty five house-hold heads were enrolled in this st by us of simple random sampling

Methods: The study employed an analytical descriptive cross sectional lesign utilizing both quantitative and qualitative data collection methods. A pretested structure que nnaire, Focus Group Discusions (FGDs) and Key Informant Interviews (KII) guides were used for data collea $\urcorner$. De criptive statistics and Chi square tests and Fisher's exact tests were computed where applicable. Data th the FGDs and Klls were analyzed using NUID.IST

Results: Significant associations between kno vledge demographic factors i.e. age $(p=0.011)$, education level $(p=0.046)$, were reported. Handwashing af er the toilet $(p=0.001)$, having a toilet facility at home $(p=0.014)$; raring animals at home $(p=0.031)$, housetiolds be affected by floods $(p=0.005)$ and frequency of visits to the paddies ( $p=0.037$ ) had a significant a sociation with respondents practices and schistosomiasis infection. Further significance was reported on househ ts beind affected by floods during the rainy season $(p<0.001)$, sources of water in a household $(p<0.047)$ and having o porary water body in the area $(p=0.024)$ with increase in schistosomiasis infection. Results revealed that ndents practices were not significantly associated with gender $(p=0.060)$, marital

Conclusions: This st dy re eals th at knowledge about the cause, transmission, symptoms and prevention of schistosomiasis amon, e rvm. a population was inadequate, and that this could be a challenging obstacle to the elimination of histoson is in these communities. Due to various dominant risk factors, different control strategies should be d sign. Therefore, there is a need for integrated control programme to have a lasting impact on transmission of schls somiasis infection. Control programs like mass drug administration need to go beyond antihelmi "ic reatment and that there is a need of a more comprehensive approach including access to clean water, sanitatio, nd bygiene. School and community-based health education is also imperative among these communities

* Correspondence: jmwai@kemri.org

Kenya Medical Research Institute, Box 54840-00200, Nairobi, Kenya 
(Continued from previous page)

Abbreviations: ESACIPAC, Eastern and southern Africa centre of international parasite control; FBOs, Faith based organizations; FGDs, Focus group discussions; HBM, Health belief model; JICA, Japan international cooperation agency; KAP, Knowledge attitude and practices; KEMRI, Kenya medical research institute; KIls, Key informant interviews; SPSS, Statistical package for social sciences; STHs, Soil transmitted helminthes; WHA, World health assembly; WHO, World health organization

\section{Background}

In 2001 a resolution was passed during the 54th World Health Assembly (WHA) with the target (for member states) to regularly administer anthelmintic drugs to at least $75 \%$ and up to $100 \%$ of all school-aged children at risk of morbidity due to schistosomiasis by 2010 [1]. In the same year, the World Health Organization (WHO) assembled an expert committee to refine the global strategy for the prevention and control of schistosomiasis. Since then, millions of school-aged children have received praziquantel against schistosomiasis [2]. Even though it has limitations because older population segments are insufficiently addressed, and hence new knowledge on prevention and control of schistosomiasis infections is minimal [2].

In Kenya, more than 6 million people, or approximately $23 \%$ of the total population, are infected with urinary or intestinal schistosomiasis [1]. In 2005, Ke 1 yan Ministries of Health and Education initiated a th s ? control programme with the aid of Japan Internati Co-operation Agency (JICA) and Kenya in tical Re search Institute (KEMRI). The programme was oeting S. mansoni and Soil transmitted hel ninthes (ST/S) in school age children. After sensitizin and educating the community health officers and educa off.cers in the district, 43,928 school age child from 86 schools were de-wormed with praziquantel and an dazole by trained school teachers [3]. Prion the de-worming, baseline prevalence and int ity of nasitic infections were determined throagh ex nination of stool samples of class three cbis on (age ange 9-14 years). A follow up study of five hort primary schools was carried out to monitor tise effectiveness of the control progran ar four consecutive years. The prevalence of par tic infections in the five cohort schools จา \% $\%$ for S. mansoni before treatment [4]. Howe uncr was an overall parasitic re-infection rate of $16 \%$ or S. mansoni, 6 months after treatment. The trend of re-infection continued after treatment to $22 \%$ in the second year, $31 \%$ in the third year and $17 \%$ in the fourth year [4]. Although the program achieved significant results, there is a continuous challenge of disease re-establishment after completion of program [5]. Mwea irrigation scheme in Kirinyaga County, where transmissions of schistosomiasis, is relatively high has a prevalence of $47.4 \%$ [3].
Knowledge, Attitudes and Practices in relation disease are critical in establishing effect contrc ${ }^{\prime}$ measures. However, data on the knoviedge, itude, and practices (KAP) of populations in endemi areas in Kenya with regard to schistosom sis are not available. Community awareness and olve. are considered as one of the cardinal trols for success and sustainability of any disease on progyamme [3]. Within this context, the present study ny to evaluate the KAP towards schistosmia $s$ in the Mwea Population. It is hoped that the will provide new information about the schisto niasis-related KAP of the targeted populatio will add new insights about the prevention and contron of this devastating disease in Kenya.

\section{Nic ods}

study rea

- study was conducted in Mwea irrigation scheme locazed in Kirinyaga County, central Kenya. Administratively, the new upgraded Kirinyaga County has two districts (Mwea East and Mwea West). The county is located about $100 \mathrm{~km}$ north east of Nairobi, Kenya. It covers an area of $513 \mathrm{~km} 2$ and it is estimated to have 51,444 households and a total population of 176,261 persons. The mean annual rainfall in this area is in the range of 1200-1600 $\mathrm{mm}$ per year and varies by the time of year. Mwea West district, where the study was conducted has two locations (Kangai and Thiba) and seven villages. The main socio-economic activity in this area is rice farming, which is done by gravity flow irrigation using water from river Thiba and Nyamindi. Mwea west district is endemic for both S. mansoni and Soil transmitted helminths (STH).

\section{Study design}

The study employed descriptive cross-sectional design adopting both qualitative and quantitative data approaches for assessing Knowledge, Attitude and Practices on schistosomiasis prevention and control in Mwea division of Kirinyaga Sub County.

\section{Study population}

The division was selected based on schistosomiasis endemicity in the area after doing a consultation with the District Public Health Officer and previous studies conducted in the area in the control program [3]. The study 
population will be selected on the basis of availability during the time of study.

\section{Sample size determination}

The minimum sample size will be computed using the formula by Fischer et al. [6].

The current prevalence is unavailable, thus an assumed prevalence of $50 \%$ will be used in the computation of the minimum sample size required for this study.

$$
\mathrm{n}=\frac{\mathrm{z}^{2} \alpha \mathrm{pq}}{\mathrm{d}^{2}} \text { Where }
$$

$\mathrm{Z}_{\alpha}=$ standard normal deviate $=1.96$

$\mathrm{p}=$ estimated prevalence. $=0.5(50 \%)$

$\mathrm{q}=(1-\mathrm{p})=0.5$

$\mathrm{d}=($ Precision $)=0.05$

$$
\mathrm{n}=\frac{(1.96)^{2}(0.50)(0.50)}{0.05^{2}} \quad \mathrm{n}=384.16 \text { approximately } 385
$$

participants

$385 \times 1.2($ design effect $)=461$ participants is the minimum sample size required for the study.

\section{Sampling procedure}

Three villages were purposively sampled based on high schistosomiasis prevalence for the study [3]. The number of households to participate, in each of the three villages were selected with a probability proportionate to thoir sizes and Mianya which has 1200 households was epresented by 301 households, Murubara has 500 an represented by 126 and Mbui Njeru which h a tota 135 households was represented by 34 hou el

\section{Selection of households}

In the quantitative component, simp andor sampling technique was applied to sel at the ruseholds from each village. The number of houss per sub-location depended on the house 1 size. The household heads were interviewed in ach ouseb sld, in the absence of the household herd aur epresentative was interviewed using th tructury questionnaire.

\section{Question aire}

An inte vas hastionnaire was used for the ho hold ds. Issues pertaining to socio-demographic ara eristic, water usage and sanitation, knowledge, attiv es and practices related to schistosomiasis infection, hous factors (such as type of construction of the house, type of floor inside house, sanitary conditions, waste disposal, acceptability and willingness to use the current preventive and control measure was used. Questionnaires were administered with both closed ended and open ended questions to capture elements of quantitative and qualitative data respectively. The questionnaire was administered using the local language and translated to English and Kiswahili.

\section{Qualitative data}

\section{Key informant interviews}

Stratified purposive sampling technique was used to select key personalities i.e. local administration, head teachers, opinion leaders, religious and group leaders and health officers. In each village, schools were sf reted for each division and the headmasters for the selected schools were interviewed in any one school. $\mathrm{P}$ osive selection was done in the village. The village elde area member of parliament or councilor health fficers in the local health facilities and crurch $r$ mosque leaders were also interviewed. At east 10 key informant interviews were conducted ir th three administrative locations, totaling up to 30 h rvic. The key informant guide that was evelope was pre-tested and amended accordingly ased to interview the above selected participants in va vs aspects. The guide was used to explor th individual knowledge, attitude and practices on it sis infection. The KII guide helped in explorin the insights of the real issues in regard to fa influencing the prevention and control of schistosomiasis , ifection from the informants.

A total of 18 in-depth interviews were conducted with op $n$ leaders from three administrative locations. Fourt en of the participants were male and four female. h. respondents mean age was 50, the youngest was 26 years old and the oldest was 75 years old. Majority (6) of respondents were farmers and teachers were three while three were village elders and three social group leaders with three business people. All (18) respondents were Christians, 17 were married and one was single.

\section{Focus group discussions}

Focus group discussions were conducted and led by trained moderators and note-takers fluent in the local languages on the above selected participants. The researcher developed themes and sub-themes on the subject of discussion. The themes and sub-themes developed were used to probe the members, while the note takers were recording gestures, assent, expressions, and other non-verbal information that maybe coming out. An evaluation was done at the end of the meeting by the researcher to validate the information collected. Discussions were gathered on two digital voice recorders and transcription were done by voice recognition software called Dragon voice recognition then typed into Ms Word and analyzed using the NUDI.ST NUIRO.6 software.

A total of 12 FGDs were done in all the three administrative locations, with each of the administrative locations having four FGDs each. The participants were asked to attend a specially arranged session of 30 to 45 min for a focus group discussion. The FGDs participants included single sex adult (36 years and above) and 
youth (18 to 35 years) male and female participants of homogenous characteristics. The FGDs were further categorized into gender (male youth and female youth and female adult and male adult). The adults had to be between 36 years of age and above. There was no exclusion in terms of language for this category Study participants were randomly selected from pools of individuals that met the inclusion criteria. The youth, whether male or female had to be between 18 and 35 years of age and able to speak either English or Swahili. Each FGD contained a minimum of 8 and a maximum of 12 participants. Community health workers, familiar with the villages, helped to mobilize participants for the study. Further screening was done on site to make sure that participants met the inclusion criteria before obtaining consent, and that they were fully representative of the different villages.

\section{Quality assurance}

Quality assurance measures included training enumerators and data entry clerks on the survey instruments, field testing with a special focus on a 'real-life' situation, as much as possible so as to improve the process and to enhance the understanding of the study team. Field supervisors were also engaged to immediately review questionnaires on a daily basis and to rectify any inconsistencies that may arise. Data Cleaning s) multi-stage process. The data was cleaned in miredia after data entry in MS Access, data was ntinuali exported to excel and fed into SPSS duringana, until the final report was completed.

\section{Data management and analysis}

Quantitative data collected $\mathrm{w}$ entered into the Ms Excel and Access software. Statisty $/$ malysis was done after data validation. cript e statistics including mean, or median, fro en and proportions were appropriately generated. square test was used to test associations be, en var, oles. Bivariate analysis was performed to iden the factors significantly associated with the KAP variablys among the studied population. A $P$ valu 0 was considered to be statistically sigur rant.

Dat collected from qualitative interviews was transo ea vurbatim into Microsoft Word. The research team Ken checked the consistency of the transcripts against the audio files to ensure accuracy of the transcribed files. The cleaned transcripts were then imported into qualitative text analysis software NUID.IST NUIRO.6 This software allowed the data to be coded systematically. Qualitative data was analysed using content and thematic analysis to identify emerging themes. The process of analysis involved familiarization with the data, development of initial codes based on the research questions and issues emerging from data, refinement of codes and their allocation to broad themes. Data was then stored in electronic storage devices like DVDs, USB, files containing the data were encrypted and access was only authorized PI to ensure quality control.

\section{Results}

Socio-demographic characteristics of the responde.

The results indicating socio-demograph characteri, ics of the respondents are presented in Table Out of the 400 and 65 respondents, there wo a highe amber of females $(63.9 \%)$ while males wer $36.1 \%$ in the three divisions, with a significant $d$ ' Fere between the genders. There were also gnt nt differences in the categories of age, mari status, 1 gion, occupation and education level. The najo $(70.0 \%)$ of the participants were married cor ed with, $0.0 \%$ who had never married. In the s cte communities, the majority of the residents were ta ers $79.1 \%$ while less that $1.0 \%$ were unemplo d Prima -educated residents accounted for $67.0 \%$, whin rest had either, no formal education, secondary caucation or postsecondary. Notably, the maof res.dents (99.6\%) were predominantly Christians ith Muslims and others constituting only $0.2 \%$.

\section{Knowledge about schistosomiasis, symptoms, transmission, prevention and control among Mwea population}

From the analysis, over half of the participants (58.71\%) indicated that the most common disease in the area was schistosomiasis. Majority of the respondents (92.9\%) stated that they were aware of schistosomiasis. A third of the participants (39.87\%) indicated health workers as the main source of information. Another third of the participants (30.51\%) mentioned stomach ache as the most common sign and symptom of schistosomiasis. Approximately $41 \%$ of the respondents stated that the disease was transmitted through contact with infected water while about $14.04 \%$ did not know the medium of transmission. Study results reveal that majority of the respondents or a member of their household (70.97\%) had suffered from schistosomiasis. Slightly above a third of the participants $(34.49 \%)$ indicated the use of toilet facility as a way of preventing schistosomiasis, and for those already infected over half of the respondents $(51.79 \%)$ indicated that prescribing to schistosomiasis medication would avoid the risk of re infection. With regard to intervention strategies for schistosomiasis, slightly below half of the respondents $(49.25 \%)$ indicated that community intervention programmes existed, with a third of the participants $(31.6 \%)$ stating that the intervention programmes were government initiatives as indicated on Table 2. 
Table 1 Socio-demographic characteristic of respondents

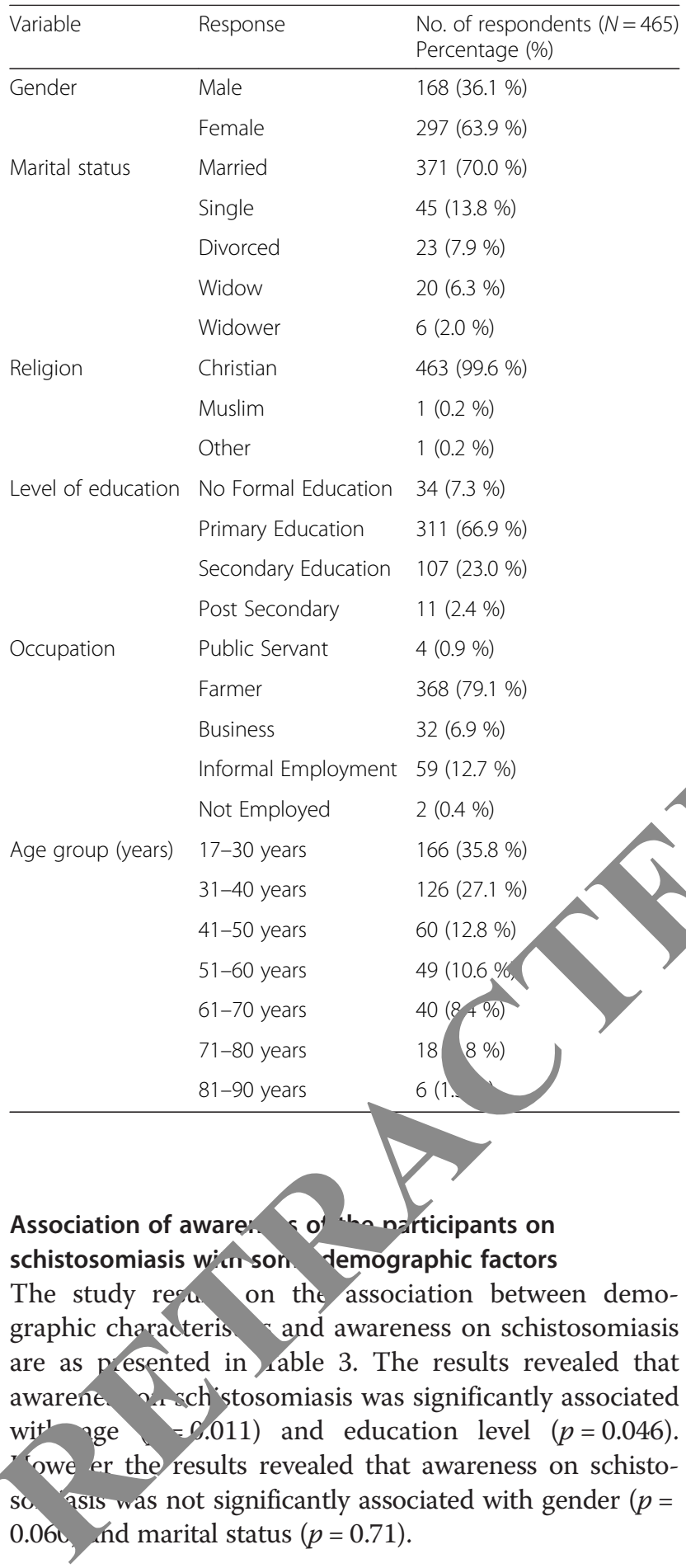

\section{Qualitative data presentation}

\section{Assessment of knowledge and awareness}

Avenues of information The FGDs with community members revealed that the majority of the participants had heard about schistosomiasis before. The sources of information included schools, posters, radio and community gatherings (baraza), with the health workers the most mentioned. A 37-year-old male casual labourer (informal employment) from Mianya said, "I heard about it through the community health workers, they normally visit us a lot especially when there are barazas at the chief's camp for health talks especially on schistosomiasis."

\section{Preferred sources of information}

With regard to spreading information abo schis osomiasis, participants mentioned a few sensitizat methods that they felt would work best in eir community: a 40year-old female farmer fror $\mathrm{Mu}$ ara said: "Door to door is best because the illa elders know each and every one of their villa and the, an do it easily...." A 37-year-old male farn er L Mianya said: "I wish they can use billboards ur those $r$ al areas it is the best one because you sf as y "walk."

\section{Knowledg ut sciistosomiasis}

Adult male $/ \mathrm{G}_{\mathrm{s}} \mathrm{s}$ indicated that some of the common diseases in the area were (as mentioned by participants); Scm somiasis, Malaria, and high blood pressure and the i ain symptoms (as mentioned by participants); nxting blood, blood in stool, stomach ache, head ache, dizziness and joint aches. Our study revealed that the majority of the participants felt they did not have adequate information about schistosomiasis. A 30-year-old female business owner from Mbuinjeru said: "Some are informed while others are not, depending on the literacy level. If you didn't go to school then you can't be informed about it." A 26-year-old male youth in Mianya said: "Me personally, I don't think that am well informed about it, because I only know that it is being caused by snails in the infested areas but what about the symptoms and the medications? I don't know."

Some of the participants had some information on how the disease can be prevented. For example, a 27 year-old adult female from Mbuinjeru said: "I think by washing hands before eating, entering the rice paddies with gum boots can help in prevention." A male youth from Murubara: "For example, if I apply jelly oil before entering the rice paddies then I won't be infected."

But lack of knowledge also turned out to be expensive for the community economically. This was echoed by one of the male respondents from the key interviews who reported that 'due to lack of knowledge the community do face problems when they are infected with Schistosomiasis for it often causes death and also a lot of energy is lost in terms of finances, much time is consumed hindering one from participating in economic growth and it impairs growth in children' 43 years old village elder from Mbuinjeru division. 
Table 2 Knowledge about schistosomiasis, symptoms, transmission, prevention and control among Mwea population

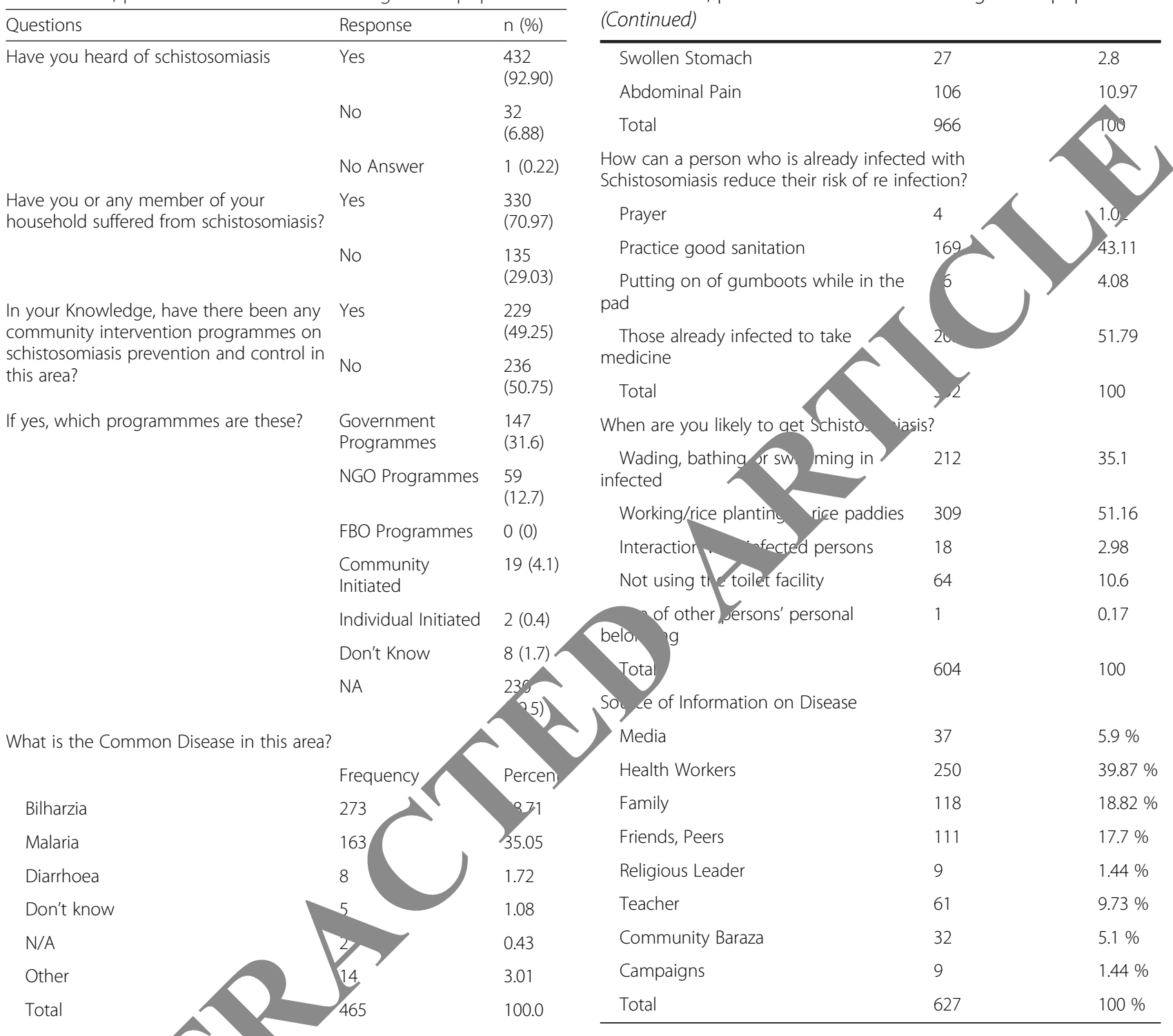

How can a person pr vent him, celf

from getting Schiros iasis?
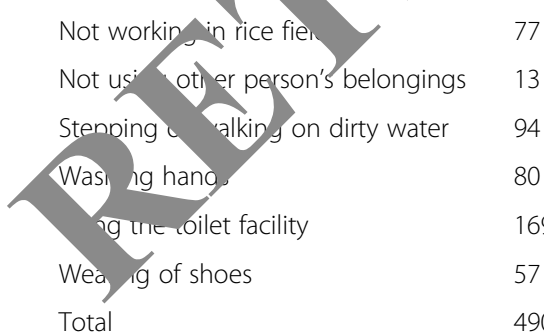

Which of the following signs and symptoms did you or members of your family experience?

$\begin{array}{lll}\text { Stomach ache } & 285 & 29.5 \\ \text { Vomiting } & 115 & 11.9 \\ \text { Diarrhea } & 221 & 22.88 \\ \text { Bloody Stool } & 212 & 21.95\end{array}$

Table 2 Knowledge about schistosomiasis, symptoms, transmission, prevention and control among Mwea population Continued)

How can a person who is already infected with Schistosomiasis reduce their risk of re infection?

\section{Practice good sanitation} pad

Those already infected to take

hen are you likely to get Schisto, iasis?

Wading, bathing or sm ming in 212

1.16

Interaction mected persons

2.98

of other „uersons' personal

of Information on Disease

Media $5.9 \%$

Health Workers

$39.87 \%$

Family

$17.7 \%$

Religious Leade

$.44 \%$

$9.73 \%$

$\%$

$100 \%$
15.71

2.65

19.18

16.33

34.49

11.63

100

\section{At risk groups}

It was the general view of participants that there is no particular gender or age that is more at risk compared with others. They attributed this to modernization where both women and men do more or less the same tasks and have the same levels of exposure as explained by a 55-year-old female farmer in Murubara "I think both male and female. Because nowadays, people believe that it is gender equality. What men can do, ladies also try." This was echoed by a 37-year-old farmer from Mbuinjeru, "As for me, I think anybody can get infected by this disease (schistosomiasis), whether it's a child or an adult and especially those people whose main work constantly involves water." A few however, bearing in 
Table 3 Association of awareness of schistosomiasis with some demographic factors

\begin{tabular}{lllll}
\hline Factors & Awareness & Total & $\begin{array}{l}\text { Statistical } \\
\text { Significance }\end{array}$ \\
\cline { 2 - 3 } & Yes & No & & \\
& $\mathrm{n}(\%)$ & $\mathrm{n}(\%)$ & & \\
\hline
\end{tabular}

Gender

$\begin{array}{lllll}\begin{array}{l}\text { Male } \\ \text { Female }\end{array} & 158(94.0) & 7(6.0) & 168(100) & p=0.060 \\ \text { Age } & 268(90.2) & 29(9.8) & 297(100) & \\ 17-30 & 144(86.7) & 22(13.3) & 166(100) & p=0.011 \\ 31-40 & 123(97.6) & 3(2.4) & 126(100) & \\ 41-50 & 53(88.3) & 7(11.7) & 60(100) & \\ 51-60 & 46(94) & 3(6) & 49(100) & \\ 61-70 & 37(93.9) & 2(6.1) & 40(100) \\ 71-80 & 18(100.0) & 0(0.0) & 18(100) \\ 81-90 & 4(66.7) & 2(33.3) & 6(100) & \end{array}$

Education

$\begin{array}{lllll}\text { Not Educated } & 30(88.2) & 4(11.8) & 34(100) & p=0.046 \\ \text { Primary } & 304(97.7) & 7(2.3) & 311(100) & \\ \text { Secondary } & 107(100.0) & 0(0.0) & 107(100) & \\ \text { Post Secondary } & 8(72.7) & 3(27.3) & 11(100)\end{array}$

Marital Status

$\begin{array}{llll}\text { Married } & 344(92.7) & 27(7.3) & 371(100) \\ \text { Single } & 39(86.7) & 5(13.3) & 45(100) \\ \text { Divorced } & 19(82.6) & 4(17.4) & 23(100) \\ \text { Widow } & 20(100.0) & 0(0.0) & 20(100) \\ \text { Widower } & 5(83.3) & 1(16.7) & 6\end{array}$

mind gender roles, felt that a particula end r was more at risk "For me, if I may reflect an how we grew up, men..., male children were the poop no were really affected by schistosomiasion idn't know any girl suffering from schistosomiasis, cal + toll whether they were infected since I did net o. rve it-perhaps they hid it as girls. So it is a nen why would realize that we were passing out blood ictims of bilharzia. The reason why we are nostly affect,d is that we expose ourselves in areas no vat when we go to graze animals or when we plas "o while girls are always at home." said a 1-ye r-old farmer from Mbuinjeru. FGD youth female in ateu-ice farmers, and children as the group that tena. $\checkmark$ get the disease more with challenges faced from the disease (as mentioned by participants); Weakness, unable to eat, going to the toilet many times, some people become bed ridden. Though adult male FGDs showed that everybody was at risk of getting the disease.

\section{Assessment of attitudes}

One of the factors that the participants mentioned and that could pose as a barrier in schistosomiasis control is the attitude of community members toward those infected with the disease. A 42-year-old male farmer in Murubara said: "They can judge you and mistake it for other diseases like HIV." A 47-year-old female in Mbuinjeru put it succinctly: "when you suffer from those symptoms like diarrhea and swollen stomach, the think that you are HIV positive." A female youth ir Mianya said: "I think when you become sick, there are th s you can't share with your spouse like blankets."

The youth female FGDs thought that ets she uld be build, they should come together ara duila ilets in the paddies as a community and that the governyent needs to be more involved by building nore 1, trines, taking care of existing latrines ara ducan the community on health education mo often 42 years old farmer in Mianya said "our $P$ Cop don't live using latrines in the paddies, majority would ro. home to use latrines and some do not mild l, y just diarrhea in the paddies."

\section{Seeking $t$ atment}

The majoilty he participants thought that treating schistosomisis is very expensive. The youth female disions inc.cated that seeking treatment is costly and its $\mathrm{L}$ e consuming. Participants indicated visiting the alth facility for treatment and drugs but some opted to se herbal treatment which they found cheap. Comnunity members opted to optimize the door to door campaign by the health worker as reported by a 40 -yearold administrator from Mianya, 'the community have advanced a step forward in the recent days out of the tireless activities of our community health workers who go door to door to campaign and teach our community on general health issues and even give our children dewormers'.

\section{Susceptibility and severity}

More than half of the participants were of the opinion that schistosomiasis is a serious disease, and that their activities exposed them to infection. These sentiments were reflected by a 25-year-old female youth in Mianya division "Where I come from it is a problem because, next to our home we have a river. People swim there ...." A 35-year-old female from Mbuinjeru went on to elaborate "Shistosomiasis is not a joke, reason being that it also brings with it headache, diarrhea of bloody stool, and as you urinate blood you end up losing a lot of blood. So it comes along with many infections to your body. You are always weak even standing up to walk becomes a problem." Similar thoughts were echoed by a 40-year-old male administrator from Murubara. "It's very serious because any disease can kill if not treated in time, so according to me schistosomiasis can kill and therefore it's a very serious disease." 


\section{Assessment of practice}

Use of sanitation facilities and hand washing ( $p=0.014, p=$ 0.001)

Most of the community members thought that they are the main cause of spreading the disease. For example, one of the respondent who is a farmer aged 60 years from Murubara Division reported that 'the community in large numbers do not use pit latrine and they usually dig shallow holes which after filling they take a long time to prepare another one'. A village elder who is 43 years old from Mianya also lamented that the community around me do use toilet but in most cases they forget to wash their hands after visiting the toilet which is a link to one of the diseases like diarrhea'.

This was further echoed by one of the respondent from the key informant interviews who reported that' there is need for the community to be sensitized on how to use the toilet facilities for not many do wash hands after visiting the toilet.'72 year old retired teacher from Murubara.

Seventy five year old chairman in one of the organizations reported that' most of the community members working in paddies have no toilets, hence they go to the canals or in the rice fields to relieve themselves'. A local administrator to the area also lamented that 'I would say that the community within my area of jurisdiction are conversant with using toilet for about $60 \%$ resides 1 . each have a toilet facility only that some sense of hyg. need be conveyed to many because about q of thes people do not remember to wash their hands a) visiting the toilet before eating.

\section{Wearing protective gear $(p=0.142)$}

On wearing of protective gean 51-years-old administrator from Mbuinjeru division re, $d$ that in actual fact, practices of wearing rotec ive gears while in the rice paddies is inevi $V^{\prime}$, naybe they may be introduced to farm or in ture for there has never been such commodi $a$ ver sino rice farming was invented in Mwea scheme.

A 56-y ar-old Dire,cor at a local factory reported that' they are ned a most people do not know the importan f usin or tective wears they say they are too heavy r. $g \mathrm{~m}$ boois and hand gloves will make them work si. $v$ in paddies and they are so expensive'.

Or of the respondents aged 26 also reported this on wearing protective gear the community at large do not wear any protective gear because the paddies are very deep'.

Household compound affected by floods $(p=0.005)$ and water for use in the household

A common practice by the community members included, fetching water for household use from canals, drainage, paddies this was from the youth male FGDs. On households being affected by floods, one of the key informants reported that 'most of the area is flooded with water in rainy season. Many people do not use toilet facilities' a 50 year old female farmer from Mianya division. Another respondent who is 40 years of ag $\bullet$ from also added that 'many toilets within the region re $3 \mathrm{ft}$ or $4 \mathrm{ft}$ they stay for 3 months in dry spells but dur. rainy season they are over flown with water all ove. He village'.

A 33 years old male instructor firom rubara reported that 'the area is swampy and you dis $3 \mathrm{ft}$ deep and after the rainy season water, ods all over the community making it dirty. There o th u ver available becomes contaminated he ce was. for there is no piped water.

\section{Association bet ree ractices and having suffered from} schistosomiasis

Table 4 indicates relationship between practices and having su from schistosomiasis infection. There was an asscla, on $(p=0.037)$ between frequency of visits to the paddies and having suffered from schistoSOn sis infection. There was a significant association hetwe $n$ washing of hands after visiting the toilet and 1 ing suffered from schistosomiasis infection ( $p=$ 0.001). Further, the results show that having suffered from schistosomiasis infection had a significant association with having a toilet facility at home, $(p=0.014)$; raring animals at home $(p=0.031)$ and household being affected by floods $(p=0.005)$. Study indicate no significant association between working in the paddies ( $p=$ $0.144)$, not wearing protective footwear $(p=0.142)$ and having suffered from schistosomiasis infection.

\section{Discussion}

Study findings showed that $39.87 \%$ of the respondents indicated that they had heard about the disease from the healthcare personnel. However, a study in Senegal [7] showed low awareness of intestinal schistosomiasis among the population. Despite 7 years of health education interventions using a diversity of communication outlets including radio, television and posters, a previous study in Senegal revealed that although $86 \%$ of the respondents stated that they had heard about schistosomiasis, only $30 \%$ had adequate knowledge about the symptoms and modes of transmission of the disease [7]. The present study revealed poor knowledge about the modes of transmission and preventive measures of schistosomiasis; with $34.49 \%$ of the respondents indicating that use of toilet facility would prevent one from getting schistosomiasis infection. In western Kenya, a previous study found that some of the participants knew snails and poor sanitation contributed to the spread of the 
Table 4 Distribution of respondents' practice and having suffered from schistosomiasis infection

\begin{tabular}{|c|c|c|c|c|}
\hline \multirow[t]{2}{*}{ Factors } & \multicolumn{2}{|c|}{ Having suffered from Schistosomiasis infection } & \multirow{2}{*}{$\begin{array}{l}\text { Total } \\
\text { n (\%) }\end{array}$} & \multirow{2}{*}{$\begin{array}{l}\text { Statistical } \\
\text { Significance }\end{array}$} \\
\hline & $\begin{array}{l}\text { Yes } \\
\text { n (\%) }\end{array}$ & $\begin{array}{l}\text { No } \\
\text { n (\%) }\end{array}$ & & \\
\hline \multicolumn{5}{|c|}{ Working in the paddies } \\
\hline Yes & $325(74)$ & $113(26)$ & $438(100)$ & \\
\hline No & $17(65)$ & $10(35)$ & $27(100)$ & \\
\hline \multicolumn{5}{|c|}{ Frequency of visiting paddies } \\
\hline Frequently & $284(76)$ & $91(24)$ & $375(100)$ & \\
\hline Rarely & $38(61)$ & $25(39)$ & $63(100)$ & \\
\hline \multicolumn{5}{|c|}{$\begin{array}{l}\text { Wearing protective footwear } \\
\text { while in the paddies }\end{array}$} \\
\hline Yes & $5(56)$ & $4(44)$ & & $p=0.142$ \\
\hline No & $320(74)$ & $111(26)$ & & \\
\hline \multicolumn{5}{|c|}{ Handwashing after toilet visiting } \\
\hline Yes & $176(64)$ & $99(36)$ & & $p=0.001$ \\
\hline No & $160(84)$ & $30(16)$ & 100) & \\
\hline \multicolumn{5}{|c|}{$\begin{array}{l}\text { Sanitation facility available } \\
\text { at home }\end{array}$} \\
\hline Yes & $323(73)$ & $119(27)$ & $442(100)$ & $p=0.014$ \\
\hline No & $20(87)$ & $3(13)$ & $23(100)$ & \\
\hline \multicolumn{5}{|c|}{ Raring Animal at home } \\
\hline Yes & $178(80)$ & & $224(100)$ & $p=0.031$ \\
\hline No & $168(70)$ & & $241(100)$ & \\
\hline \multicolumn{5}{|c|}{$\begin{array}{l}\text { H/Hold compound affected } \\
\text { by floods }\end{array}$} \\
\hline Yes & $258(78)$ & (22) & $333(100)$ & $p=0.005$ \\
\hline No & $84(64)$ & $48(36)$ & $132(100)$ & \\
\hline
\end{tabular}

disease, but lacked understanding o he tansmission cycle [7]. Hence, it is clear th the lack of this knowledge among the targeted populitic ay create an additional burden and cos controlling the disease and may cause the failur $f(t)$ chistosomiasis eradication programme.

Although th ajority the respondents had heard about schistosomia the results showed that awareness about the symptoms, ways of transmission and preventive ana participants was gen lly $\mathrm{p}-\mathrm{T}$ he present study was carried out in enrmic areas nat underwent the active control and prevo on surveillance by Japan International Cooperation Age $/$ (JICA together with GoK line ministries $(\mathrm{MoH}$, MoE) which may explain why $92.90 \%$ of the respondents had heard about the disease. This is also consistent with the finding that $70.97 \%$ of the respondents had declared history or a member of their household having suffered from shistosomiasis which supports the endemicity of infection in these communities. Study findings revealed that $28.50 \%$ of the respondents mentioned stomachache as the main signs and symptoms.
Conversely, previous studies from Brazil and Ethiopia reported diverging information where the majority of the subjects were able to associate these symptoms with the infection $[8,9]$. Similarly, it is also worth noting that knowledge about the symptoms of schistosomiasis among the respondents was negligible, as only $22.88 \%$ of them mentioned diarrhea and $21.95 \%$ blood in stools. This could be attributed to the disease being frequently confused with other intestinal infections exhibiting similar symptoms, such as amoebic dysentery, which is common among the targeted populations [10, 11]. The theoretical foundation in the Health Belief Model (HBM), integrates people's knowledge, perceptions, attitude and practices to a disease in establishing trends of infection [12].

The study further revealed a significant association $(p \leq 0.05)$ between washing of hands after visiting the toilet with having suffered from schistosomiasis infection. The current study was consistent with studies conducted in Gondar and Babile [12, 13], where there was significant association between intestinal parasitic infections and hand washing practice. A study conducted in 
Brazil reported that daily contact of open water source results in higher rate of infection by S. mansoni [14].

The current study indicates that, availability of toilet facility at home was significantly associated with having suffered from schistosomiasis infection. This does not concur with a study from Yemen which reported that the absence of a functioning toilet in the house was significantly associated with the prevalence of schistosomiasis and this was in accordance with other previous studies [15].

The findings of the present study showed that raring animals at home was significantly associated with having suffered from schistosomiasis infection. Results of a survey in Xinzhuang, indicated grazing cattle, digging vegetables, cutting grass in the field, and raising cattle by free grazing are some of the risk factors for schistosomiasis hence greater infection rates [16].

The study results further indicated that households being affected by floods was significantly associated with having suffered from schistosomiasis infection. While it is clear that sanitation breaks the transmission cycle of many diseases, the season can have impacts on the sanitation facilities themselves with heavy rains causing pit latrines and sewerage systems to flood and become inoperable and possibly contaminate the environment. A study by $\mathrm{Wu} \mathrm{XH}$ et al. $1 \mathrm{1}$ ] indicated that the number of acute cases with s. st somiasis japonica was markedly higher in y-ars c acterized by floods; on average, 2.8 timeo re case were observed when compared to years that tho ingtze River had normal water levels [17].

The present study reveal that ge ler, marital status, wearing protective gear and working the ice paddies were not significantly associa with having suffered from schistosomiasis. This conclirs $m /$ a study by Hany Sady et al. [18] which fon no ignificant difference in the prevalence of sc- tos mincis between male and female participants and $\mathrm{n}$. tal status. The study indicated female as more one to shistosomiaisis infection than men, these could $\mathrm{t}$ tributed to females being responsible for etching wat, $r$ and washing clothes and utensils at these s s urces, and therefore, have similar expoc to ${ }^{c t} / v e$ stages. Other studies elsewhere have so i borted significantly higher infection rates among fe. les cumpared to their males counterparts $[19,20]$.

Se rotection during agricultural work plays an important role of reducing the risk of infection, at least in principal. However, this present study indicated no significance between wearing protective gear and having suffered from schistosomiaisis infection. This concurs with a study by which revealed that PPE wearing behaviours were not improved by the intervention that the project put in place. It still scored lowly. When asked about the reason for not using any protection, most people responded that "however useful in interrupting transmission, it was uncomfortable and inconvenient to wear rubber gloves or boots while working in the fields". While this illustrates the difference between understanding the benefit and modifying behaviour, as suggested in other studies of occupationally-related behaviour shange [21], it also raises the issue of the practicalitif of sustained personal protection in an inherently rish nvironment. Spear et al. [22] argues that a focu on environmental improvements and monic ng syst mis to signal early risks of infection are betce lon ter/h solutions than personal protection in ural China as they are in occupational settings worldwid 22].

The study results reveal th. wor on the rice paddies was not significantl assocla d with having suffered from schistosomiasis (1 does not concur with a study by Bukenya et al. [23] whic dicated that schistosomiasis mansoni in the s dy area is closely linked to working in the rice padi

\section{Conclusion:/sign, Icance}

This study reveals inadequate knowledge, attitude and pra es concerning schistosomiasis among the Mwea opu tion, which could be a challenging obstacle to the - ey our towards the elimination of schistosomiasis from Kenya. Schistosomiasis infection is still a major problem with regard to prevention and control in Mwea. Thus, there is a great need for a proper health education intervention and community mobilization in order to enhance prevention and instill better knowledge concerning the transmission and prevention of schistosomiasis. Providing efficient health education to people residing in schistosomiasis endemic areas is imperative for an effective and sustainable control programme in order to save the lives and future of the most vulnerable population in Kenya.

These findings support an urgent need to start an integrated, targeted and effective schistosomiasis control programme with a mission to move towards the elimination phase. Besides periodic drug distribution, health education i.e. handwashing and community mobilisation, provision of clean and safe drinking water, introduction of proper sanitation are imperative among these communities in order to curtail the transmission and morbidity caused by schistosomiasis. Emergence response during floods should also be used as a mitigation strategy in curbing new infections. Screening and treating other infected family members should also be adopted by the public health authorities in combating this infection in these communities. This study recommends a focus on change in practices in the community to complement existing efforts aimed at creating knowledge and awareness on schistosomiasis. 


\section{Study limitations}

\section{Since it was a Cross-Sectional study, it was therefore dif-} ficult to infer causality.

\section{Acknowledgements}

The authors would like to acknowledge Director KEMRI for providing the Internal Research Grant that facilitated the project. Vote of thanks goes to the study participants and the study team as a whole. We wish to express our sincere thanks to the District administrators in Kirinyaga County, staff of the Ministries of health and the community members for facilitating the smooth running of the project in Mwea. We are also grateful to Danvers Omolo of DNDI for his statistical inputs. This paper is published with the permission of the Director KEMRI.

\section{Funding}

This study received financial support from Kenya Medical Research Institute (KEMRI), Eastern and Southern Africa Centre of International Parasite Contro (ESACIPAC). The Kemri Internal Research Grant No. IRG/072/3.

\section{Availability of data and materials}

That all data used in the manuscript is available for sharing.

\section{Authors' contributions}

JM-conceived of the study, participated in its design coordination, and helped to draft the manuscript. MB-participated in the design of the study and helped to draft the manuscript. SN-participated in the design, coordination and helped to draft the manuscript. All authors read and approved the final manuscript.

\section{Authors' information}

JM-is a Research Scientist at ESACIPAC/KEMRI. SN-is a Chief Research officer at ESACIPAC/KEMRI. MB-is a Research officer at ESACIPAC/KEMRI.

\section{Competing interests}

The authors declare that they have no competing interests.

\section{Consent for publication} Not applicable.

\section{Ethics approval and consent to participate}

This study was approved by the KEMRI Ethical Re protocol No. (2061). The study used questionnaires results of each questionnaire being kept in ctrict con the study was voluntary and one could wit many point. The purpose of the study and its objectives were explain d to to al authorities, opinion leaders, village elders, and comp members. Informed consent was obtained from the participati resp idents. abjects were assured about confidentiality of information them and personal identifiers were removed from th data set ore, analysis.

Received: 27 Jana ry 2u Accepted: 12 August 2016

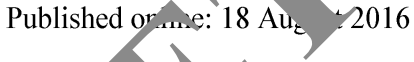

Reference.

1. World He Orgznization. Weekly epidemiological record 30 April No.18. 2o 85:15\% Available at http://www.who.int/wer/en/. Accessed 7 Dec

2. शท aer werf MJ1, de Vlas SJ, Brooker S, Looman CW, Nagelkerke NJ, hema JD, Engels D. Quantification of clinical morbidity associated with sct,rstosome infection in sub-Saharan Africa. Acta Trop. 2003:86(2-3):125-39

3. Kihara J, Muhoho N, Njomo D, Mwobobia I, Joslyne K, Mitsui Y, et al. Drug efficacy of praziquantel and albendazole in School children in Mwea, Central Province, Kenya. Acta Trop. 2007;102:165-71.

4. Kihara J, Muhoho N, Mwobobia I, French D, Churcher S, Njoroge P, et al. A four-year follow-up of school children after mass-treatment for Schistosomiasis and Soil Transmitted Helminths in Mwea, Central Kenya. Afr J Health Sci. 2012;23:232-7.

5. Drake J, Jukes H, Sternberg J, Bundy P. Geohelminth infections (Ascariasis, Trichuriasis and Hookworm): cognitive and developmental impacts. Semin Pediatr Infect Dis. 2000;11:245-51.
6. Fischer A A, Laing J E. and Strocker J E. Handbook for Family Planning, Operation Research Design in Sampling. Population Council 1998: 40-45.

7. Sow S, de Vlas SJ, Mbaye A, Polman K, Gryseels B. Low awareness of intestinal schistosomiasis in northern Senegal after 7 years of health education as part of intense control and research activities. Trop Med Int Health. 2003:8:744-9.

8. Uchoa E, Barreto SM, Firmo JO, Guerra HL, Pimenta Jr FG, Costa MFLe. The control of schistosomiasis in Brazil: an ethno-epidemiological stud onthe effectiveness of a community mobilization program for health Aucation. Soc Sci Med. 2000;51:1529-41.

9. Geleta S, Alemu A, Getie S, Mekonnen Z, Erko B. Prevalence of urin schistosomiasis and associated risk factors among Ab bo primary sC children in Gambella Regional State, southwestern $\mathrm{E}$, ia: a cros. sectional study. Parasit Vectors. 2015;8:215. doi.10 186/s 71-015,0822-5.

10. Azazy AA, Al-Mahbashi TY, Al-Mekhlafi HM. P evalence of in , mal and blood parasites among school children in ha'a and Al-Mahweet provinces, Yemen. Yemen Med J. 200\%:4:50

11. Alyousefi NA, Mahdy MA, Mahmud $n$ YA. associated with high prevalence of intestinal protozo infe s among patients in Sana'a City, Yemen. PLoS One. 2011;6(7) Y044. doi:10 Y/journal.pone.0022044.

12. Gelaw A, Anagaw B, Nigy sie evalence of intestinal parasitic infections and risk factors among schoolch, at the University of Gondar Community Schoo hwest Ethio, a: a cross-sectional study. BMC Public Health. 2013;13

13. Tadesse G. The p risk factors among olchildren in Babile town Eastern Ethiopia. Ethiop J Heal De $005 ; 19(2): 1$

14. Marçal Ju mu mansoni in are, of low transmission. II. Risk factors for infection. Rev Inst Med Trop S o Paulo. 1993;35(4):331-5.

world Healt, Organisation. Prevention and control of schistosomiasis and transmitted helminthiasis. Technical report series. Geneva: World Health Or nisation; 2002. p. 912

Zb Ju XN, Lin DD, Wang TP, Chen HG, Guo JG, Liang YS, Qiu DC, Dong XQ, ISZ. Control strategy of schistosomiasis and key points in the 12th five-year plan in China. Chin J Schisto Control. 2011;23:1-4.

Wu XH, Zhang SQ, Xu XJ, Huang YX, Steinmann P, Utzinger J, Wang TP, Xu J, Zheng J, Zhou XN. Effect of floods on the transmission of schistosomiasis in the Yangtze River valley, People's Republic of China. Parasitol Int. 2008:57(3):271-6. doi:10.1016/j.parint.2008.04.004.

18. Hany S, Hesham M, Al-Mekhlafi, Mohammed AKM, Yvonne ALL, Rohela M, Johari S. Prevalence and Associated Factors of Schistosomiasis among Children in Yemen: Implications for an Effective Control Programme. PLoS Negl Trop Dis. 2013;7(8):e2377.

19. Satayathum SA, Muchiri EM, Ouma JH, Whalen CC, King CH. Factors affecting infection or reinfection with Schistosoma haematobium in coastal Kenya: survival analysis during a nine-year, school-based treatment program. Am J Trop Med Hyg. 2006;75:83-92.

20. Rudge JW, Stothard JR, Basáñez MG, Mgeni AF, Khamis I. Micro-epidemiology of urinary schistosomiasis in Zanzibar: Local risk factors associated with distribution of infections among schoolchildren and relevance for control. Acta Trop. 2008;105:45-54.

21. Hu GH, Hu J, Song KY, Lin DD, Zhang J, Cao CL, Xu J, Li D, Jiang WS. The role of health education and health promotion in the control of schistosomiasis: experiences from a 12-year intervention study in the Poyang Lake area. Acta Trop. 2005;96:232-41.

22. Spear RC, Seto EY, Carlton EJ, Liang S, Remais JV, Zhong B, Qiu D. The challenge of effective surveillance in moving from low transmission to elimination of schistosomiasis in China. Int J Parasitol. 2011:41:1243-7.

23. Bukenya GB, Nsungwa JL, Makanga B, Salvator A. Schistosomiasis mansoni and paddy-rice growing in Uganda: an emerging new problem. Ann Trop Med Parasitol. 1994;88(4):379-84. 